\title{
Are Drosophila melanogaster populations under a stable geographical differentiation due to the presence of $P$ elements?
}

\author{
G. Periquet,* \\ S. Ronsseray $\dagger$ and \\ M. H. Hamelin*
}

\author{
* I.B.E.A.S. Faculté des Sciences, Parc Grandmont \\ 37200 Tours, France. \\ † Génétique des Populations, T 42-Université Paris 6 \\ et 7, 2 place Jussieu F 75005 Paris, France.
}

In order to simulate the outcome of the $P-M$ status of Eurasian populations of Drosophila melanogaster, the evolution of experimental mixed-strains was monitored for up to 50 generations. The results were compared with the evolution in natura of European populations sampled in 1981-83 and 1986-87 over a similar period of time. Different combinations of $P$ and $M^{\prime}$ strains, $Q$ and $M^{\prime}$ strains, $M^{\prime}$ and $M^{\prime}$ strains and $M$ and $M^{\prime}$ strains were set up at $25^{\circ} C$ and duplicated at $13^{\circ} \mathrm{C}$ night- $21^{\circ} \mathrm{C}$ day. The possibility of a change towards a $P$ type only appeared with the introduction of the strong $\boldsymbol{P}$ strain Harwich into Eurasian strains. Strains with strength similar to that of Harwich are not currently found in wild populations. With the introduction of weak $P$ and $Q$ strains of the strength presently observed in western Europe, experimental populations evolved slowly towards a $Q$ state or a weak $M^{\prime}$ state. $M^{\prime}-M^{\prime}$ mixed populations resulted in strong $M^{\prime}$ strains, as was the case for $\boldsymbol{M}-\boldsymbol{M}^{\prime}$ populations. In these cases. $P$ sequences were not eliminated. In wild populations both genetic and molecular analyses showed no significant differences, over a five year period, for $G D$ sterility potentials, for total $P$ copy number or for distribution of the full-sized and $K P$ elements. Changes in Eurasian populations are probably taking place at a very low rate and may even have stopped, leading to a quasi-stable differentiation over the continent. During the different steps of progressive invasion of $P$ transposable elements, several deleted elements developed and natural selection may have acted on them. The possibility of the selection of different types of regulatory mechanisms according to the presence of different kinds of derivative elements, leading to a world-wide differentiation between $P-Q$ and $M^{\prime}$ strains is discussed.

\section{INTRODUCTION}

In the $P-M$ system of Drosophila melanogaster, the syndrome of hybrid dysgenesis (inducing gonadal sterility, high mutation level, etc.) is understood to be related to the activity of the $P$ element family of transposons (reviewed by Engels, 1989). $P$ element structures can be classified into two broad types: autonomous (complete) elements of $2.9 \mathrm{~kb}$, and non-autonomous elements that usually have sustained internal deletions of varying sizes.

Strains of Drosophila may be characterized on the basis of two properties related to the phenotypic effects of their $P$ elements. Strains are specific in their ability for mobilizing $P$ elements that are in an unregulated state. This ability is referred to as " $P$ activity potential". Strains may also vary in their property to regulate or suppress the activity of the autonomous $P$ elements present in their genomes. This property is referred to as " $P$ susceptibility". It covers the joint action of all mechanisms affecting $P$ element regulation, including that of cytotype (Engels, 1979).

Based on these properties, strains may be classified into four broad types, according to their phenotypic characteristics in diagnostic test crosses and the number of $P$ elements they possess.

$P$ strains have low to high levels of $P$ activity potential. In addition they also have low levels of $P$ susceptibility. $Q$ strains have extremely low levels of both $P$ activity potential and $P$ susceptibility ( $<5$ per cent) (Kidwell, 1979). Individuals of the $P$ type or of the $Q$ type have 25-60 copies of $P$ sequences (complete and/or deleted) per haploid genome (Bingham et al., 1982).

$M$ and $M^{\prime}$ strains rarely have any significant level of $P$ activity potential. $M$ strains are devoid of any $P$ elements and have extremely high $P$ element susceptibility. $M^{\prime}$ strains carry $P$ sequences, from a few up to 50 copies per haploid genome. Most, if not all, of these sequences are defective (Bingham et al., 1982; Black et al., 1987; Izaabel et al., 1987). $M^{\prime}$ strains vary for $P$ element suscepti- 
bility from extremely high to moderately low (Anxolabéhère et al., 1985). A subtype of $\boldsymbol{M}^{\prime}$ strains, harbouring several copies of a specific deletion derivative element (the $K P$ element) has also been described (Black et al., 1987). These $K P$ elements may interact, perhaps by inhibition of the transposase of active elements, to repress the level of induced hybrid dysgenesis.

Surveys of natural populations have shown pronounced geographical differences (Anxolabéhère et al., 1982, 1984, 1985; Kidwell, 1983; Boussy et al., 1988). All present populations that have been tested have at least some genomic $P$ elements. $P-Q$ strains predominate in the Americas and Central Africa, whereas $M^{\prime}$ strains predominate in North Africa, in Europe and Asia. In Europe and Central Asia, the frequency of $P-Q$ populations rapidly declines from west to east. The number of $P$ element copies gradually declines in the same way from about 30 copies per haploid genome in France, to ten copies or less in Central Asia (Ronsseray et al., 1989). KP elements are common in all of these populations (Black et al., 1987).

$P$ elements show high frequencies of transposition when destabilized in dysgenic crosses $(M$ females $\times P$ males). Although such events may be expected to reduce the fitness of dysgenic hybrids (Kidwell et al., 1977; Mackay, 1986; Fitzpatrick and Sved, 1986), there is evidence from studies of mixed populations and transformed lines that high levels of transposition often lead to an increase in the frequency of $P$ elements (Kidwell et al., 1981; Anxolabéhère et al. 1986, 1987; Daniels et al., 1987; Kidwell et al., 1988). The general conclusion from these studies is that changes can occur towards either the $P$ or $M^{\prime}$ state, with the changes towards $P$ predominating. These results are consistent with the recent spread of $P$ elements in populations of D. melanogaster (Anxolabéhère et al., 1988a). Independently of the question of the date of arrival of $P$ elements in this species: recent (in the last fifty years, Kidwell, 1979) or more ancient (in the last million years, Engels, 1989), the capacity for rapid invasion of the genome by $P$ elements as observed in laboratory experiments poses the problem of the spread of these elements in natural populations and of the fate of the global geographical distribution observed today.

An understanding of the dynamics of mixed populations is therefore of interest for the study of the spread of $P$ elements under natural conditions. We report here the results of experiments in which samples of different natural $P, Q$ and $M^{\prime}$ strains were introduced into different $M^{\prime}$ and $M$ strains in order to simulate a process of a steppingstone invasion in Eurasian populations. The results are compared with the evolution in natura of populations sampled on the continent, over a similar period of time.

\section{MATERIALS AND METHODS}

\section{Drosophila strains}

Wild strains derived from diverse areas between France and mid-Asia were used. They are listed in each experiment. In general, each strain was derived from a large number $(>30)$ of individuals. They were kept at $20^{\circ} \mathrm{C}$ under standard laboratory conditions, in mass cultures of about 500 individuals. The mixed population experiments began in 1984, using strains collected mainly in 1983. The analyses of 1986-1987 samples were made during the first to sixth generation following capture.

The two reference strains used to test dysgenic potential were Harwich (strong $P$ ) and Canton-S (Strong $M$ ).

\section{Estimation of induced GD sterility}

Determination of the $P-M$ status of tested strains was based on the standard test for measuring gonadal sterility potential (Kidwell, 1983). Thirty virgin individuals of the strain tested were massmated at $28 \cdot 5^{\circ} \mathrm{C}$ as follows:

\section{Cross A: Canton $\mathrm{S} q q \times \delta \widehat{o}$ tested \\ Cross $A^{*}$ : $q 9$ tested $\times$ Harwich $\delta \delta^{*}$}

Fifty $\mathrm{F} 1$ females were dissected to estimate the percentage of dysgenic ovaries $(100 \times$ number of dysgenic ovaries divided by the total number of ovaries scored) and to classify the strain. Cross A provides a measure of the $P$ activity potential of the tested strain and cross $\mathrm{A}^{*}$ a measure of its $P$ susceptibility. In order to characterize each strain, its $P$ activity potential and its $P$ susceptibility, obtained by the standard crosses, are given in brackets after the strain denomination: e.g. Harwich [100-0], Canton S [0-100].

\section{Mixed populations}

Experimental populations were set up in order to simulate a migration flux from West to East. Three groups of populations were established. The first involved 20 individuals (ten non-virgin females and ten males) from one $P$ strain, with 100 
individuals (50 non-virgin females and 50 males) from one $M^{\prime}$ strain. Twelve mixed populations were founded on this basis using combinations of three "invader" strains (Harwich, Raleigh [23-0; U.S.A., 1982], and Aniane [10-0; France, 1983]), and four "recipient" strains (Tautavel [0-32; France, 1983], Krasnodar [0-92; Eastern Europe, U.S.S.R., 1983], Chimkent [0-99] and Alma-Ata [0-97] both from Central Asia, U.S.S.R., 1983 and 1981 respectively]).

The second group of populations corresponds to a mixture in the same proportions as above, of different western $M^{\prime}$ strains and the most eastern $M^{\prime}$ strains. The six mixed populations resulted from the combination of three "invader" strains (Tautavel [0-32; France, 1983], Cěské-Budějovice [0-86; Czechoslovakia, 1983], and Krasnodar [092; U.S.S.R., 1983] and the two "recipient" strains (Chimkent and Alma-Ata).

For both groups, the parents were allowed to lay eggs for two successive periods of five days on axenic medium. The first set of 18 populations was set up at $25^{\circ} \mathrm{C}$ and maintained at this temperature for all subsequent generations.

The second set was set up at an alternating temperature of $13^{\circ} \mathrm{C}$ (night) and $21^{\circ} \mathrm{C}$ (day) on a 12:12 light: dark cycle. Each of these 18 populations were maintained under these conditions for all subsequent generations.

In order to follow the fate of the $P-M$ status of these mixed populations, their $P$ activity potential and $P$ suceptibility were repeatedly measured until the fiftieth generation.

The third group of mixed populations does not correspond to a situation found today in the wild. Eight mixed populations were set up, in the same proportions as described above, resulting from the combination of four "invader" $M^{\prime}$ strains (AlmaAta, Chimkent, Uman [0-96; U.S.S.R., 1983] and Berlin [0-78; F.R.G., 1983] and two "recipient" $M$ strains (Crimea [0-100; U.S.S.R., 1936] and Gruta [0-100; Argentina, 1950-55]). Two replicates were established as previously described, but each of them were maintained at $25^{\circ} \mathrm{C}$ for all subsequent evolution, until the 24 th generation at which point $P$ copy number was estimated by in situ hybridization.

\section{Hybridization techniques}

The presence of $P$ element sequences was tested in natural populations by Southern blot using the p $\pi 25.7$ BWC $P$ element as a probe. DNA was extracted from 150 female flies per strain and Southern blots were performed using standard techniques (Maniatis et al., 1982). Filters were washed at high stringency $(0 \cdot 1 \times \mathrm{SSC}, 0 \cdot 5$ per cent SDS; $\left(65^{\circ} \mathrm{C}\right)$. Genomic DNA samples were digested with AvaII, run on $1 \cdot 2$ per cent agarose gels, blotted onto hybond membranes and hybridized with ${ }^{32} \mathrm{P}$ nick translated $\mathrm{p} \pi 25.7 \mathrm{BWC}$.

\section{In situ hybridization}

The $P$ element copy number of natural populations was measured by in situ hybridization to polytene chromosomes. Tritium dCTP labelled $\mathrm{p} \pi 25 \cdot 1$ DNA (O'Hare and Rubin, 1983) containing the full length $P$ element (plus genomic DNA from the $17 \mathrm{C}$ region) in a pBR 322 plasmid was used as the probe. In order to measure the $P$ copy number, 4-5 slides were made for each natural population and 2-3 slides for each replicate of any $M-M^{\prime}$ mixed population. 5-6 nuclei were analysed per slide. The copy number per haploid genome was determined by crossing females of the tested strain with Gruta strain males (devoid of $P$ copies) and the squash procedure was performed on F1 larvae. These measures were carried out for Eurasian strains collected in 1986-87, in order to compare these results with values obtained from samples collected in 1982-83 on the same continent (Ronsseray et al., 1989).

\section{RESULTS}

\section{Evolution of mixed populations from $P$ and $M^{\prime}$ strains}

Fig. 1 shows the evolution of $P$ activity potential and $P$ susceptibility of the experimental populations founded by the introduction of $P$ flies into the different Eurasian $M^{\prime}$-strains. In most cases the population reached a quasi stable equilibrium after 20 generations. Parental strains were also stable during the experiments.

At $25^{\circ} \mathrm{C}, P$ activity potentials in populations mixed with the strong $P$ strain Harwich increased rapidly during the first 5 to 10 generations. The final levels of $P$ activity potential, as measured by percentage $G D$ sterility, ranged from 30 to 96 per cent. This was related to the $P$ susceptibility of the recipient strains such that the stronger the $P$ susceptibility of the recipient strain, the stronger the $P$ activity potential obtained in the mixed population. There was a delay in the development of $P$ element regulation, but in general $P$ susceptibility decreased rapidly over the first ten generations and reached the low levels characteristic of $P$ strains 

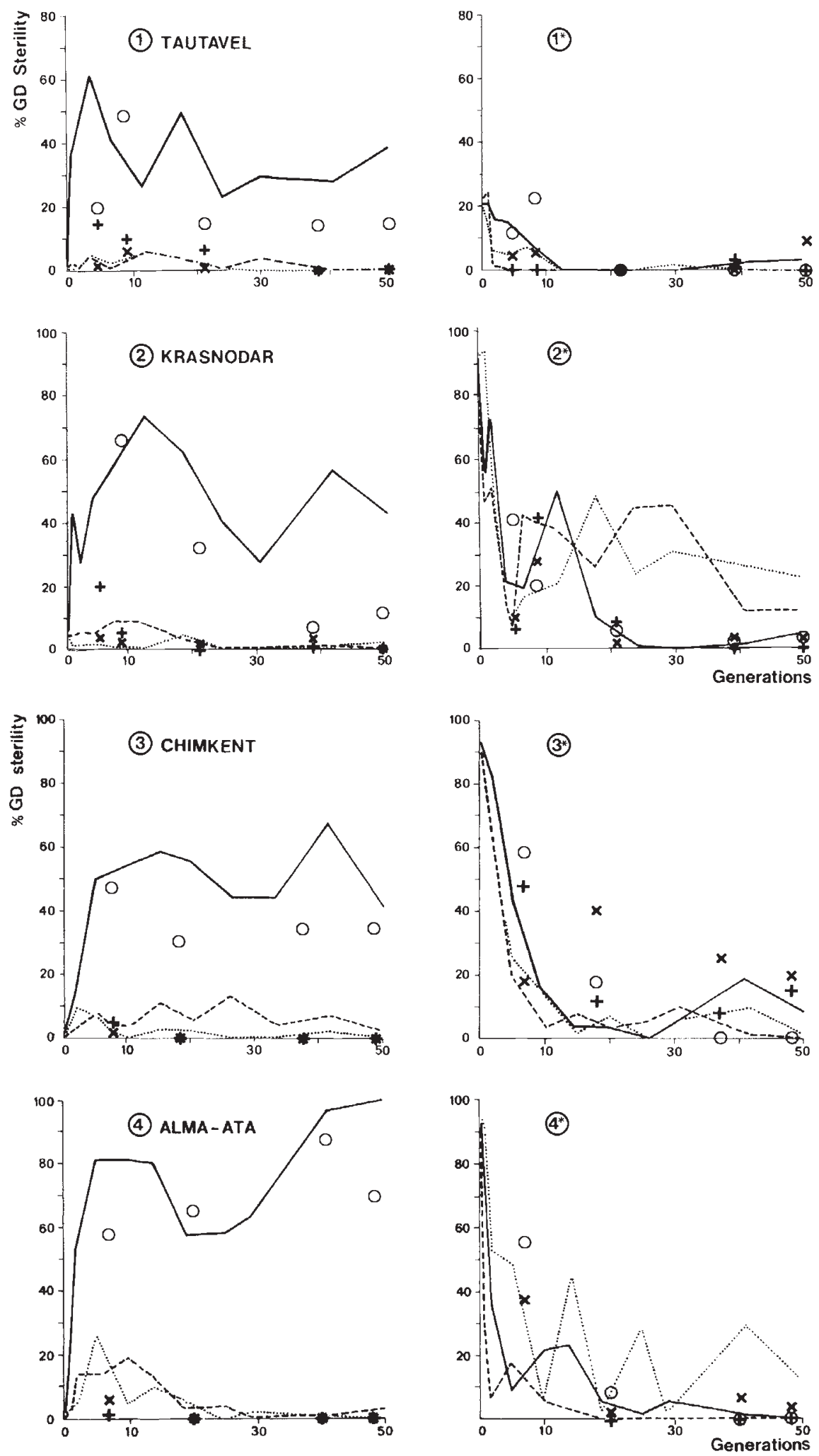

Figure 1 Evolution of $P$ activity potential (cross A) and $P$ susceptibility (cross $\mathrm{A}^{*}$ ) in $P-M^{\prime}$ mixed populations founded from one-sixth of either Harwich (_-), Raleigh (- -) or Aniane (...), with five-sixths of the recipient strain indicated, and maintained at $25^{\circ} \mathrm{C}$. The evolution of each replicated population, followed at $13^{\circ} \mathrm{C}$ night $-21^{\circ} \mathrm{C}$ day, is presented only as dots with: Harwich (O), Raleigh ( + ) and Aniane $(x)$. 
in about 20 generations. This agrees with previous observations on mixed populations (Anxolabéhère et al., 1986).

No high $P$ activity potential developed in populations mixed with the weak $P$ strain Raleigh. Some significant levels (approximately 10 per cent) were observed with the most susceptible strains (Chimkent and Alma-Ata), but they rapidly disappeared. Over the same period $P$ susceptibility decreased and the mixed populations finally tended to evolve the status of $Q$ strains.

A similar pattern evolved in populations mixed with the $Q$ strain Aniane. Mixed populations presented very low levels of $P$ activity potential $(<1$ per cent) and a longer delay in the development of $P$ element regulation (reduced $P$ susceptibility). After 50 generations two mixed populations were of the $Q$ type, but the other two retained low levels of $P$ susceptibility (approximately 20 per cent), as can be observed in some natural $M^{\prime}$ populations.

At the alternate temperatures of $13^{\circ} \mathrm{C}$ night $/ 21^{\circ} \mathrm{C}$ day, the outcome was similar for all mixed populations, leading to $P$ strains with Harwich, $Q$ strains with Raleigh and $Q$ or weak $M^{\prime}$ strains with Aniane. These results show that, with the strains used, the final status depends mainly on the balance between the strength of the $P$ activity potential of the introduced strain and the $P$ susceptibility of the recipient strain. However, in the mixed populations involving the Harwich strain the final level of $P$ activity potential in all populations was lower at $13^{\circ} / 21^{\circ} \mathrm{C}$ than at $25^{\circ} \mathrm{C}$. This suggests a possible role for temperature in the establishment of a strain equilibrium.

\section{Evolution of mixed populations from different $M^{\prime}$ strains}

Fig. 2 shows the evolution of $P$ susceptibility of experimental populations founded by the introduction of $M^{\prime}$ flies from France, Czechoslovakia or the Western U.S.S.R., into $M^{\prime}$ strains from the Eastern U.S.S.R. In no case was any $P$ activity potential observed. However, $P$ susceptibility levels of the mixed populations were affected for 10 to 30 generations. Following this, a quasistable equilibrium was observed, the values of which ranged from 80 to 100 per cent. In most cases the final $P$ susceptibility of mixed populations was at the same level as the recipient strains Chimkent or Alma-Ata. The extent of the effects depended on the strain involved but not on the temperature.

At $25^{\circ} \mathrm{C}$, the effect lasted longest with the Tautavel strain, which presents the lowest level of
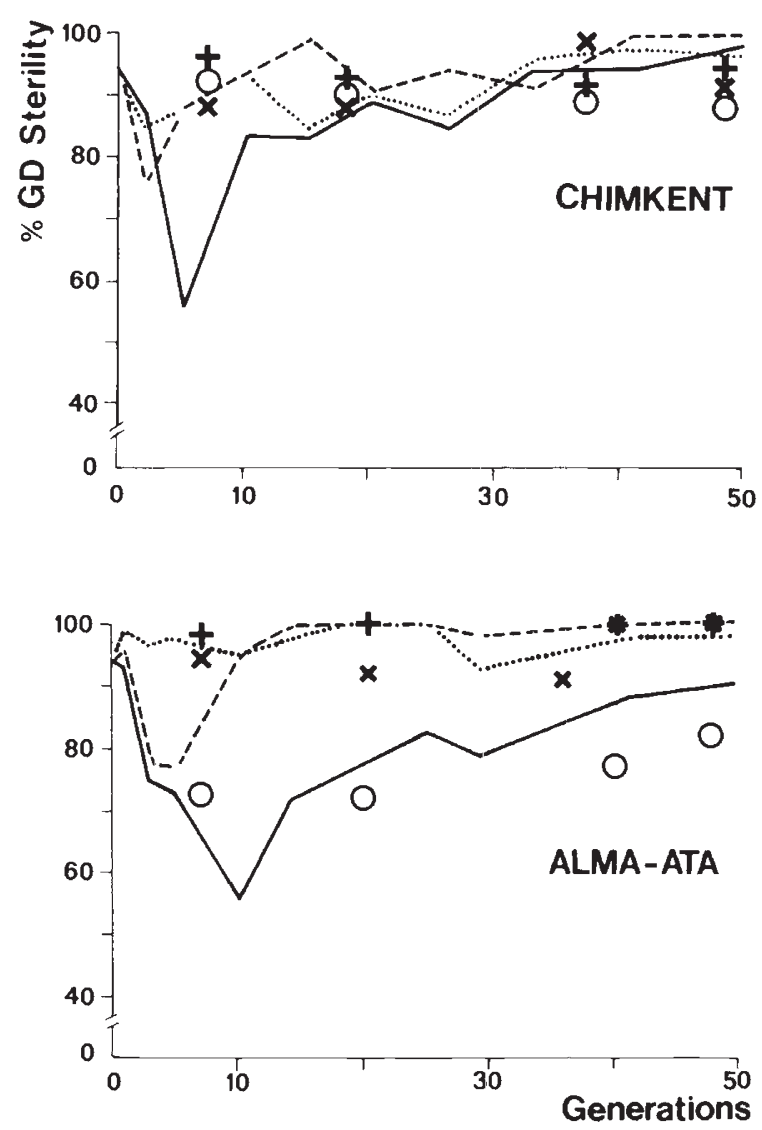

Figure 2 Evolution of $P$ susceptibility in $M^{\prime}-M^{\prime}$ mixed populations founded with one-sixth of either Tautavel $(-)$, Cèske $(---)$ or Krasnodar $(\cdots \cdots)$, and five-sixths of the recipient strains Chimkent or Alma-Ata, and maintained at $25^{\circ} \mathrm{C}$. The evolution of each replicated population, followed at $13^{\circ} \mathrm{C}$ night $-21^{\circ} \mathrm{C}$ day, is presented only as dots with: Tautavel $(O)$, Cěske $(+)$ and Krasnodar $(x)$.

$P$ susceptibility. The final level was either similar to the recipient strain Chimkent, or slightly lower with Alma-Ata.

With the Cěské and the Krasnodar strains, which have a high $P$ susceptibility, the effect was shorter or even non-existent. The final level was the same as in the recipient strains.

At the alternate $13^{\circ} / 21^{\circ} \mathrm{C}$ temperatures, the outcome was similar for all mixed populations, leading only to $M^{\prime}$ strains. As in the first set of experiments, all of the results show that the final status of the mixed populations depends mainly on the interacting strains. With $M^{\prime}$ strains no $P$ activity potential developed and only strong $P$ susceptible strains were obtained, even when one of the mixed strain had only had a weak $P$ susceptibility, as in Tautavel. 
Table 1 Evolution of mixed populations from $M^{\prime}$ and $M$ strains. Copy number of $P$ elements, per haploid genome, detected by in situ hybridization in parental strains (base), and mixed populations ( 2 replicates: R1 and R2) at the 24th generation of evolution. The value expected, under random distribution without increase in the number of elements, is indicated as the base number divided by one-sixth, the initial ratio of $M^{\prime}$ to $M$ individuals in each mixed population

\begin{tabular}{|c|c|c|c|c|c|}
\hline & & & Gruta $(5 / 6)$ & Crimea $(5 / 6)$ & \\
\hline \multirow{3}{*}{$\begin{array}{l}\text { Alma-Ata } \\
\text { base } \\
\text { expected }\end{array}$} & $(1 / 6)$ & & & & \\
\hline & $7 \cdot 7$ & R1 & $3 \cdot 0$ & $4 \cdot 5$ & mean $=3.9$ \\
\hline & $1 \cdot 3$ & $\mathrm{R} 2$ & $4 \cdot 3$ & $3 \cdot 5$ & $s=1.9$ \\
\hline \multirow{3}{*}{$\begin{array}{l}\text { Chimkent } \\
\text { base } \\
\text { expected }\end{array}$} & $(1 / 6)$ & & & & \\
\hline & $8 \cdot 8$ & $\mathrm{R} 1$ & $4 \cdot 0$ & $5 \cdot 3$ & mean $=4.4$ \\
\hline & $1 \cdot 5$ & $\mathrm{R} 2$ & - & $3 \cdot 5$ & $s=3 \cdot 2$ \\
\hline \multirow{3}{*}{$\begin{array}{l}\text { Uman } \\
\text { base } \\
\text { expected }\end{array}$} & $(1 / 6)$ & & & & \\
\hline & $17 \cdot 5$ & $\mathrm{R} 1$ & $8 \cdot 5$ & $4 \cdot 0$ & mean $=9 \cdot 1$ \\
\hline & $2 \cdot 9$ & $\mathrm{R} 2$ & $9 \cdot 0$ & $12 \cdot 5$ & $s=3 \cdot 0$ \\
\hline \multirow{3}{*}{$\begin{array}{l}\text { Berlin } \\
\text { base } \\
\text { expected }\end{array}$} & $(1 / 6)$ & & & & \\
\hline & $26 \cdot 2$ & $\mathrm{R} 1$ & $22 \cdot 0$ & $15 \cdot 0$ & mean $=16.5$ \\
\hline & $4 \cdot 4$ & $\mathrm{R} 2$ & $12 \cdot 5$ & $14 \cdot 0$ & $s=4 \cdot 7$ \\
\hline
\end{tabular}

\section{Evolution of mixed populations from $M^{\prime}$ and $M$ strains}

In the evolution of mixed populations founded by different Eurasian $M^{\prime}$ strains introduced into the Gruta and Crimea $M$ strains, no $P$ activity potential was observed. The final levels of $P$ susceptibility were generally very high ( 92 to 100 per cent), as in the parental strains, except for the BerlinGruta populations which reached an intermediate level of $P$ susceptibility (35 to 69 per cent).

In order to determine whether these experimental populations retained any $P$ elements, in situ hybridization experiments were carried out at the end of the experiment. The results are presented in table 1 and show that in all cases $P$ elements were present after 24 generations. The introduced $P$ sequences persisted through these generations as they might be expected to do in the absence of selection pressure against them. However, although the donor strain represented only onesixth of the initial population, the final number of $P$ elements was always greater than one-sixth of the number of introduced elements, being approximately half the number of elements carried by the donor strains.

\section{Evolution of Eurasian natural populations between 1982 and 1987}

Genetic and molecular investigations were carried out on the $P-M$ status of Eurasian populations collected in 1982-83 (Anxolabéhère et al., 1985; Ronsseray et al., 1989). We wanted to know the state of these populations, sampled four or five years later. This time interval roughly corresponds to 50 generations in the wild and allows comparisons between the natural evolutionary process and laboratory experiments of mixed populations.

Table 2 and fig. 3 summarize the data for wild strains collected between 1982 and 1987 from France to Central Asia. In both cases a marked difference is evident between Western Europe, with weak $P$ and $Q$ strains, and Eastern Europe and Central Asia where $M^{\prime}$ strains predominate. The measure of $P$ susceptibility shows that the gradient observed in 1982-83 has been maintained, with low susceptibility in western populations ( 0 to 5 per cent of induced $G D$ sterility), intermediate in Central Europe (30-60 per cent) and high susceptibility in eastern areas (80-100 per cent).

This gradient is related to variation in the $P$ copy number per haploid genome, as estimated by in situ hybridization. As for the phenotypic characteristics, the 1986-87 collection revealed that the genetic structures have been maintained both in the global geographical variation and in the mean copy number of elements per population.

The gradient in copy number appears also to be related to variation in the number of $P$ elements belonging to different structural classes. From the molecular analyses of Black et al., 1987 and Anxolabéhère et al., $1988 a$, it appears that in the 1982-83 Eurasian strains, $2.9 \mathrm{~kb}$ full-sized $P$ elements are present in western populations but absent or very rare in eastern ones. Conversely if each population harbours $K P$ elements, their relative number is higher in eastern populations than 
Table 2 Description of the $P-M$ status of western to eastern Eurasian populations sampled in 1981-83 and 1986-87. In order to allow comparisons with each 1986-87 sample, the strain collected at the closest longitude in 1981-83 is presented (data from Anxolabéhère et al., 1985). (For GD sterility standard deviation in no cases exceeded 5 per cent, and 3 per cent for $P$ copy number)

\begin{tabular}{|c|c|c|c|c|c|c|c|c|c|}
\hline $\begin{array}{l}\text { Strain tested } \\
(1981-83)\end{array}$ & & $\begin{array}{l}P \\
\text { activity }\end{array}$ & $\begin{array}{l}P \\
\text { susceptibility }\end{array}$ & $\begin{array}{l}P \text { copy } \\
\text { number }\end{array}$ & $\begin{array}{l}\text { Strain tested } \\
(1986-87)\end{array}$ & & $\begin{array}{l}P \\
\text { activity }\end{array}$ & $\begin{array}{l}P \\
\text { susceptibility }\end{array}$ & $\begin{array}{l}P \text { copy } \\
\text { number }\end{array}$ \\
\hline Angers & 83 & 9 & 2 & - & Ste Geneviève & 86 & 23 & 0 & $33 \cdot 0$ \\
\hline Lille & 83 & 2 & 54 & $34 \cdot 0$ & Leiden & 87 & 1 & 20 & $37 \cdot 7$ \\
\hline Tubingen & 83 & 0 & 37 & $39 \cdot 5$ & Tubingen & 86 & 0 & 48 & $34 \cdot 0$ \\
\hline Berlin & 83 & 0 & 78 & $26 \cdot 2$ & - & - & - & - & - \\
\hline - & - & - & - & - & Golubac & 86 & 0 & 89 & $20 \cdot 0$ \\
\hline Uzhgorod & 83 & 1 & 73 & - & Uzhgorod & 86 & 0 & 60 & $27 \cdot 5$ \\
\hline Gomel & 81 & 0 & 100 & - & Chernobyl & 86 & 0 & 95 & $13 \cdot 5$ \\
\hline Uman & 83 & 0 & 100 & $17 \cdot 5$ & Uman & 87 & 0 & 99 & $16 \cdot 3$ \\
\hline Magarach & 83 & 0 & 71 & - & Zaporoje & 87 & 0 & 99 & $19 \cdot 0$ \\
\hline Krasnodar & 83 & 0 & 92 & - & Brjansk & 87 & 0 & 100 & $17 \cdot 0$ \\
\hline
\end{tabular}

in western ones. Fig. 4 shows the results of Southern blot analyses of 17 Eurasian populations collected in 1986-87. Genomic DNA samples were digested with Ava $I I$ and hybridized with nick translated $\mathrm{p} \pi 25 \cdot 7 \mathrm{BWC}$. Ava II cuts four times in the complete $P$ element yielding three diagnostic bands of hybridization with sizes $0.49,0.54$ and $1.8 \mathrm{~kb}$. For the internally deleted $K P$ element, $A v a$ II cuts only three times, yielding two diagnostic bands with sizes $0 \cdot 49$ and $0 \cdot 63$. Full-sized elements are found only in western populations, but each population tested harboured $K P$ elements. The relative number of $K P$ elements is highest in eastern populations.

In conclusion, both genetic and molecular analyses showed no significant evolution of Eurasian natural populations. We found no differences in $P-M$ status, for total $P$ copy number, or distribution of the full-sized and $K P$ elements between the 1982-83 and 1986-87 samples.

\section{DISCUSSION}

The data presented here confirm earlier results on the evolution of laboratory populations set up with a mixture of $P, Q$ and $M$ or $M^{\prime}$ chromosomes (Kidwell et al., 1981; Kiyasu and Kidwell, 1984; Anxolabéhère et al., 1986) and extend them to natural populations. The possibility of a change towards a $P$ type only appeared with the introduction of the strong $P$ strain Harwich into Eurasian strains. The final level of $P$ activity potential depends on the $P$ susceptibility level of the recipient strain. In general, the resultant mixed strains have a dramatically lower level of $P$ activity potential than Harwich, except for the strongest $P$ susceptible strains (Alma-Ata). Strains with a strength similar to that of Harwich are not currently found in wild populations. With the introduction of weak $P$ and $Q$ strains of the strength presently observed in Western Europe, experimental populations slowly evolved towards a $Q$ state or a weak $M^{\prime}$ state. $M^{\prime}-M^{\prime}$ mixed populations resulted in strong $M^{\prime}$ strains, as was the case for $M-M^{\prime}$ popu. lations. In these cases, $P$ sequences were not eliminated and the copy number of elements, observed at the end of the experiment, was significantly higher than expected under random segregation of the original elements.

The outcome of mixed-populations was similar when raised at constant $25^{\circ} \mathrm{C}$ or at the alternate temperature of $13^{\circ} \mathrm{C}$ night $/ 21^{\circ} \mathrm{C}$ day. After $30-50$ generations, no significant differences were observed for $P$ susceptibility levels, but in the mixed populations initiated with Harwich the final level of $P$ activity potential was always lower at $13^{\circ} / 21^{\circ} \mathrm{C}$ than at $25^{\circ} \mathrm{C}$. This contrasts with previous results (Kidwell et al., 1988) in which the mean level of $P$ activity potential was reduced in lines raised at $25^{\circ} \mathrm{C}$, relative to those raised at $20^{\circ} \mathrm{C}$. However in this case the experimental populations resulted from the mixture of Harwich with $M$ strains devoid of any $P$ sequences. Our results suggest that the role of temperature in the establishment of a strain equilibrium depends both on 

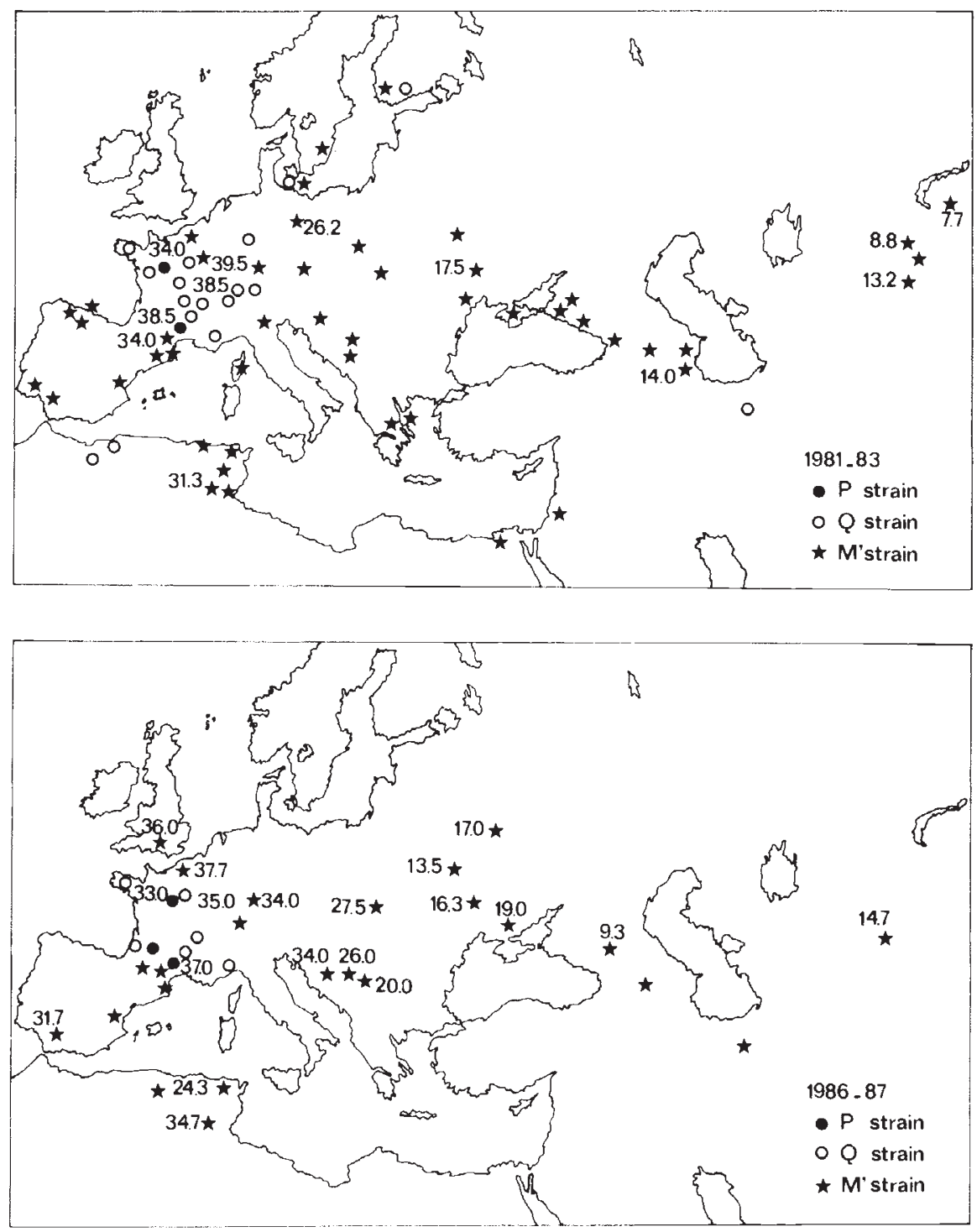

Figure 3 Geographical distribution of Eurasian populations of $D$. melanogaster according to their GD sterility potentials in the $P-M$ system and their copy number of $P$ elements per haploid genome.

the action of selection, reducing the fitness of dysgenic individuals, and on the type of elements they harbour.

The choice of a global approach to describe the population dynamics of $\boldsymbol{P}$ elements was made in our experiments in order to understand the natural evolution of Eurasian populations. The monitoring of such mixed populations allowed us to observe the mean changes resulting from the interactions between $P$ element transposition and excision, and the classical forces of population genetics, without separating the role of each com- ponent. Such mean changes are those which drive natural populations and comparisons with experimental observations will help us to understand evolution in the wild.

\section{A model for the $P$ invasion hypothesis}

Molecular analyses of $\boldsymbol{P}$ homologous elements in numerous species of the Drosophilidae family (review in Anxolabéhère and Périquet, 1987) have revealed the presence of $P$ elements in $D$. melanogaster, but not in its various sibling species. The 

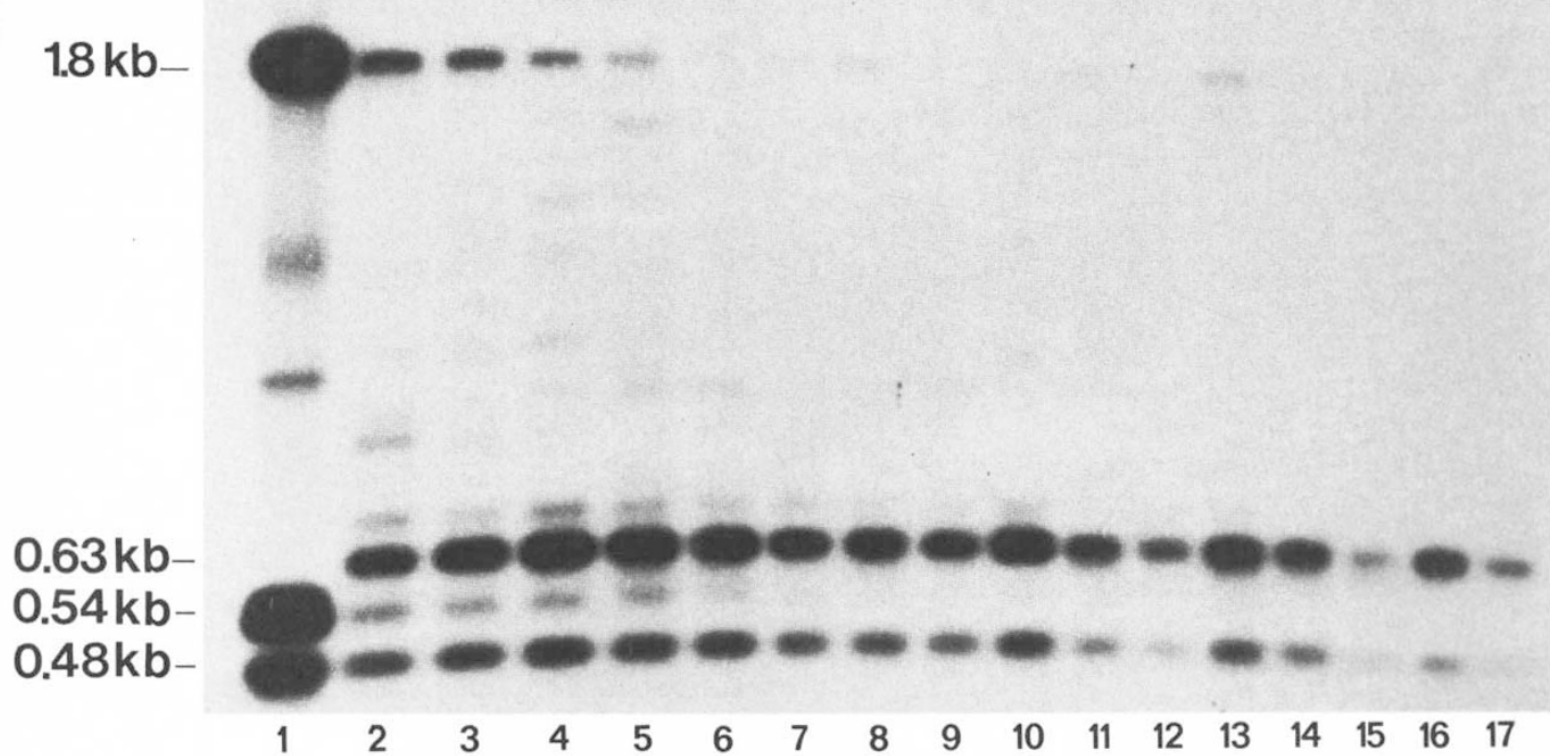

Figure 4 Structure of $P$ elements in Eurasian populations collected in 1986-87. Autoradiogram of Ava II digests of ca. $3 \mu \mathrm{g}$ of genomic DNA of each strain, probed with the plasmid p $\pi 25.7 \mathrm{BWC}$. Lane 1 is control lane containing DNA from Harwich. The remaining lanes are arranged as in table 2, in order from west to east: (2) Ste Geneviève 86, (3) Thionville 87, (4) Tubingen 86, (5) Leiden 87, (6) Oxford 87, (7) Kamenica 86, (8) Slankamen 86, (9) Golubac 86, (10) Uzhgorod 86, (11) Chernobyl 86, (12) Uman 87, (13) Zaporoje 87, (14) Brjansk 87, (15) Nalchik 87, (16) Samarkand 86, (17) Control Alma-Ata 81. The 1.8-, $0 \cdot 54$ - and 0.48 -kb fragments expected from a complete $P$ element are indicated, as are the $0 \cdot 63$ - and $0 \cdot 48$-kb fragments expected from a $K P$ element.

findings of $P$ homologues in more distantly related species (Daniels and Strasbaugh, 1986) and, more recently, of transposable elements in the $D$. willistoni species, homosequential to the $P$ element of D. melanogaster (Peterson and Kidwell, personal communication), are consistent with the hypothesis of an invasion of $D$. melanogaster by mobile $P$ elements. This invasion may be recent and may have taken place during this century, before 1950 (Kidwell, 1979, 1983). Or it may more ancient, but must have taken place after the divergence of $D$. melanogaster and $D$. simulans, approximately one million years ago (Engels, 1989). However, $P$ elements have relatively homogeneous sequences, aside from internal deletions (O'Hare and Rubin, 1983), and surveys of laboratory strains sampled on different continents since 1920 suggest that $P$ elements spread in North and South America, prior to becoming common in other parts of the world (Kidwell, 1983; Anxolabéhère et al., 1988a). On the other hand, biogeographic and genetic data suggest that $D$. melanogaster colonized the American continent only a few centuries ago, going from tropical Africa to tropical America (David and Capy, 1988).
Taken together, these data suggest that $P$ elements have recently been introduced into the $D$. melanogaster genome. This probably took place in the Americas and may have involved a neotropical species such as $D$. willistoni. Whatever the true situation, there has been a recent bottleneck in the $P$ element population, followed by the spread of these elements into the global species, presumably aided by increased human activity during this century.

The process of the $P$ invasion may be hypothesised, given data on the evolution of experimental mixed populations. The model of innovative stepping-stone invasion (Anxolabéhère et al., 1986, 1988a) proposes that several phases of invasion, mixture and new colonization by the resulting populations took place following the original contamination. At each step, $P$ elements underwent internal deletions, leading to a reduced efficiency in the resulting strain's ability to contaminate a new population. This process first occurred during the initial invasion of American populations, leading to moderate $P$ strains distributed in a gradual manner over the continent, as described by Kidwell and Novy (1985). The 
subsequent invasion of Eurasia resulted from the introduction of individuals from such strains into western Europe, leading to stable weak $P / Q$ populations, after a transient period of instability. New deletions occurred during this process and helped to lower the ratio of autonomous to nonautonomous elements in the populations radiating into the rest of Europe and Asia. This led to the $M^{\prime}$ strains found in these areas since the mid-1970s.

This hypothesis is consistent with the results of the present study, which show that the gradual decrease of $P$ activity in mixed populations depends on the type and geographical origin of the strains. It allows us to explain the striking qualitative differences in $P$ element distribution between continents and in the outcome of $P$ invasions in $D$. melanogaster.

\section{Deleted-elements and regulatory potential in natural populations}

Although very little is known about the types of regulatory mechanism existing in wild populations, it appears that the pattern of regulation of $P$ elements, at least in North America, is consistent with the development of $P$ cytotype (Engels, 1979; Engels and Preston, 1980; Kiyasu and Kidwell, 1984). However it is possible that other types of regulatory mechanism, implicating deleted elements, may restrain the development of $P$ cytotype in other areas (Black et al., 1987; Jackson et al., 1988).

In Europe and Central Asia, the presence of phenotypic and molecular clines in the distribution of $P$ elements, with weak $P$ and $Q$ strains in the west, and $M^{\prime}$ strains in the east (Anxolabéhère et al., 1985), has been confirmed by in situ hybridization (table 2 and Ronsseray et al., 1989). The total number of $P$ elements per haploid genome declines from about 30 in strains from Western Europe, to about nine from the Chimkent strain and eight from the Alma-Ata strain. This clinal distribution is consistent with the gradual invasion of polymorphic $P$ elements proposed by the stepping-stone model. It may be interpreted as a transient stage during the invasion process. As Eurasian $M^{\prime}$ strains do not appear to be able to eliminate their $P$ elements, even when mixed with $M$ strains, a possible outcome may be an increase in the copy number of $P$ elements due to migration from the west, leading to a general state in which all populations would be of the $Q$ type. However, the present results show that $M^{\prime}$ populations from Central Europe and the U.S.S.R. appear to be resistant to the introduction of $M^{\prime}$ files from westernmost areas. Thus their $P-M$ status did not change in the experimental populations, nor in the wild, over a five year period (the present study, and Anxolabéhère et $a l$, , $1988 b$ for a survey of French populations).

Although the status quo which currently exists among Eurasian D. melanogaster remain to be tested over the time, the possible mechanisms of its maintenance may be evoked. Such a mechanism might reside in the presence of $K P$ elements in all European strains (Black et al., 1987). The preponderance of this class of element may be due to a regulatory role, or to a special capacity for replicative transposition. Such elements have also been detected at high frequencies in Australian (Boussy et al., 1988) and Chinese populations (unpublished data).

$K P$ elements can be detected in North and South-American strains collected since 1954 (unpublished data). However their presence in American strains is irregular until the end of the 1960s. In France and the U.S.S.R., $P$ elements can be detected from the end of the 1960s. Some of the early French $P$ strains harbour $K P$ elements, which can be regularly found in strains collected from the 1970s onwards. Taken together with the present distribution of $K P$ elements in world-wide populations, it can be suggested that $K P$ elements, possibly formed by a unique deletion event, occured or arrived in the U.S.A. around the end of the first phase of the $P$ invasion of U.S. populations. At this time, control of $P$ mobilization by cytotypic regulation would have been almost complete. $K P$ elements were therefore not highly selected, contributing only a small proportion of the total population of $P$ elements. Nevertheless, $K P$ elements were present in samples of flies which arrived in Western Europe, China and Australia.

During the dysgenic period following the introduction of $P$ elements into the $M$ genome, natural selection would have selected for them (Black et al., 1987), on the basis of either their transpositional property or their regulatory potential, instead of the cytotypic regulation, leading to their high frequency in these areas. This hypothesis implicates a higher fitness of $K P$ elements in dysgenic conditions. This point is corroborated by competition line experiments in which Harwich automosomes were mixed with $K P$ carrying chromosomes (Black et al., 1987; Jackson et al., 1988). The lines evolved to become stable and phenotypically $M^{\prime}$. The copy number of $K P$ elements increased, suggesting that $K P$ elements alter the way in which $P$ sequences are spread. However, the fact that Harwich $\mathrm{X}$ chromosomes (rich in $P$ 
elements) were not allowed to compete with $K P$ elements in these experiments may explain why $P$ elements were not able to invade these populations. Other mixed populations founded with the whole Harwich chromosomal set evolved towards a $P$ status (present fig. 1, Anxolabéhère et al., 1986; Kidwell et al., 1988). Moreover, the fact that their mixed populations were raised at $21^{\circ} \mathrm{C}$, instead of $25^{\circ} \mathrm{C}$ as in other experiments with Harwich, reinforces the suggestion that evolution at a low temperature, with deleted elements, may discourage the formation of a high level of $P$ activity potential.

\section{CONCLUSION}

In natural populations, the different steps of the progressive invasion of transposable elements may allow the formation of new genetic material upon which natural selection can act, retaining different types of regulatory mechanisms according to the presence of different kinds of derivative elements. Such deleted elements appear to be of special importance in the evolution of transposable elements, and may have been accumulated in other systems. In the hobo system of $D$. melanogaster, striking similarities with the $P-M$ system have been shown in the temporal distribution of strains (Periquet et al., 1989a). The majority of strains derived from natural populations in the Americas and in Europe before the mid 1950s harbour few hobo homologous sequences. In contrast, all recently derived and present-day populations that have been tested carry numerous hobo elements. A recent study has shown a high frequency of a derivative-deleted element of $1.5 \mathrm{~kb}(T h)$, in all populations tested from France to China, and in the Americas, a distribution which is highly similar to that of KP elements (Periquet et al., 1989b).

Interactions between the different partners in each family of transposable elements might play a role in the dynamics of the elements, determining different patterns of distribution, both for the elements and the Drosophila populations. Thus, in a period of time which is relatively short by evolutionary standards, a world-wide differentiation may develop, due to the activity of transposable elements, and may become of great importance for the future of the species.

Acknowledgements We thank M. Golubovsky, M. G. Kidwell, F. Marec and D. Sperlich, who generously supplied their strains, and M. Cobb and C. Montchamp for helpful comments on the manuscript. This work was supported by grants from the Centre National de la Recherche Scientifique (URA 239, URA 693, PIREN), the Ministère de la Recherche et de la Technologie, and the European Communities.

\section{REFERENCES}

ANXOlABÉHÈre, D. AND PERIQUeT, G. 1987. P-homologous sequences in Diptera are not restricted to the Drosophilidae family. Genet. Iber., 39, 211-222.

ANXOlabÉHÈre, D., NOUAUd, D. AND PERIQUET, G. 1982. Etude de la variabilité du système $P-M$ de dysgénésie des hybrides entre populations de Drosophila melanogaster. C.R. Acad. Sci. Paris, 294, 913-918.

ANXOLABÉHĖRE, D., KAI, H., NOUAUD, D., PERIQUET, G. AND RONSSERAY, S. 1984. The geographical distribution of $P-M$ hybrid dysgenesis in Drosophila melanogaster. Genet. Sel. Evol., 16, 15-26.

ANXOLABÉHÈRE, D., NOUAUD, D., PERIQUET, G. AND TCHEN, P. 1985. P-element distribution in Eurasian populations of Drosophila melanogaster: a genetic and molecular analysis. Proc. Natl Acad. Sci. USA, 85, 5418-5422.

ANXOLABÉHĖRE, D., NOUAUD, D., PERIQUET, G. AND RONSSERAY, S. 1986. Evolution des potentialités dysgénésiques du système $P-M$ dans des populations expérimentales mixtes $P, Q, M$ et $M^{\prime}$ de Drosophila melanogaster. Genetica, 69, 81-95.

ANXOLABÉHĖRE, D., BENES, H., NOUAUD, D. AND PERIQUET, G. 1987. Evolutionary steps and transposable elements in Drosophila melanogaster: the missing RP type obtained by genetic transformation. Evolution, 41, 846-853.

ANXOLABÉHÈRE, D., KIDWELL, M. G. AND PERIQUET, G. 1988a. Molecular characteristics of diverse populations are consistent with a recent invasion of Drosophila melanogaster by mobile $P$ elements. Mol. Biol. Evol., 5, 252-269.

ANXOLABÉHÈRE, D., CHARLES-PALABOST, L., FLEURIET, S. AND PERIQUET, G. 1988b. Temporal surveys of French populations of Drosophila melanogaster: $P-M$ system, enzymatic polymorphism and infection by the sigma virus. Heredity, 61, 121-131.

BINGHAM, P. M., KIDWELL, M. G. AND RUBIN, G. M. 1982. The molecular basis of $P-M$ hybrid dysgenesis: the role of the $P$ element, a $P$ strain specific transposon family. Cell, 29, 995-1004.

BLACK, D. M., JACKSON, M. S., KIDWELL, M. G. AND DOVER, G. A. 1987. $K P$ elements repress $P$-induced hybrid dysgenesis in D. melanogaster. EMBO Journal, 6, 4113-4123.

BOUSSY, I. A., HEALY, M. J., OAKESHOTT, J. G. AND KIDWELL, M. G. 1988. Molecular Analysis of the $P-M$ Gonadal Dysgenesis Cline in Eastern Australian Drosophila melanogaster. Genetics, 119, 889-902.

DANIELS, S. B. AND STRASBAUGH, L. D. 1986. The distribution of P-element sequences in Drosophila: the willistoni and saltans species groups. J. Mol. Evolution, 32, 138-148.

DANIELS, S. B., CLARK, S. H., KIDWELL, M. G. AND CHOVNICK, A. 1987. Genetic transformation of Drosophila melanogaster with an autonomous $P$ element: phenotypic and molecular analyses of long-established transformed lines. Genetics, $115,711-723$.

DAVID, J. R. AND CAPY, P. 1988. Genetic variation of Drosophila melanogaster natural populations. Trends Genet., 4, 106111. 
ENGELS, W. R. 1979. Hybrid dysgenesis in Drosophila melanogaster: rules of inheritance of female sterility. Genet. Res., Camb., 33, 219-236.

ENGels, W. R. 1989. P-elements in Drosophila. In: Mobile DNA. D. Berg and M. Howe Eds., American Society of Microbiology (In press).

ENGEls, W. R. AND PRESTON, C. R. 1980. Components of hybrid dysgenesis in a wild population of Drosophila melanogaster. Genetics, 95, 111-128.

FITZPATRICK, B. AND SVED, J. A. 1986. High levels of fitness modifiers induced by hybrid dysgenesis in Drosophila melanogaster. Genet. Res., Camb., 48, 89-94.

IZAABEL, H., RONSSERAY, S. AND ANXOLABÉHÈRE, D. 1987. Temporal stability of $P-M$ polymorphism in a natural population of Drosophila melanogaster. Genet. Res., Camb., 50, 99-103.

JACKSON, M. S., BLACK, D. M. AND DOVER, G. A. 1988. Amplification of $K P$ elements associated with the repression of hybrid dysgenesis in Drosophila melanogaster. Genetics, 120, 1003-1013.

KIDWELL, M. G. 1979. Hybrid dysgenesis in Drosophila melanogaster: the relationships between the $P-M$ and $I-R$ interaction systems. Genet. Res. Camb., 33, 205-217.

KIDWELL, M. 1983. Evolution of hybrid dysgenesis determinants in Drosophila melanogaster. Proc. Natl Acad. Sci. USA, 80, 1655-1659.

KIDWELL, M. G., KIDWELL, J. F. AND SVED, J. A. 1977. Hybrid dysgenesis in Drosophila melanogaster: a syndrome of aberrant traits including mutation, sterility and male recombination. Genetics, 86, 813-833.

KIDWELL, M. G., NOVY, J. B. AND FEELEY, S. M. 1981. Rapid unidirectional change of hybrid dysgenesis potential in Drosophila. J. Hered., 72, 32-38.
KIDWELL, M. G. AND NOVY, J. B. 1985. The hybrid dysgenesis determinants in North American populations of $D$. melanogaster. Drosophila Inform. Serv., 61, 97-100.

KIDWELL, M. G., KIMURA, K. AND BLACK, D. M. 1988. Evolution of Drosophila melanogaster genomes following $P$ element contamination. Genetics, 119, 815-828.

KIYASU, P. K. AND KIDWELL, M. G. 1984. Hybrid dysgenesis in Drosophila melanogaster: The evolution of mixed $P$ and $M$ populations maintained at high temperature. Genet. Res Camb., 44, 251-259.

MACKAY, T. F. 1986. Transposable element-induced fitness mutations in Drosophila melanogaster. Genet. Res. Camb., $48,77-87$.

MANIATIS, T., FRITSC H, E. AND SAMBROOK, J. 1982. Molecular Cloning: A Laboratory Manual. Cold Spring Harbor, New York, pp. 545.

O'HARE, K. AND RUBIN, G. M. 1983. Structures of $P$ transposable elements and their sites of insertion and excision in the Drosophila melanogaster genome. Cell., 34, 25-35.

PERIQUET, G., HAMELIN, M. H., BIGOT, Y. AND LEPISSIER, A. 1989a. Geographical and historical patterns of distribution of hobo elements in Drosophila melanogaster populations. J. Evol. Biol., 2, 223-239.

PERIQUET, G., HAMELIN, M. H., BIGOT, Y. AND KAI, H. $1989 b$ Presence of the deleted hobo element $T h$ in Eurasian populations of Drosophila melanogaster. Genet. Sel. Evol., 21, 107-111.

RONSSERAY, S., LEHMAN, M. AND PERIQUET, G. 1989. Comparison of the regulation of $P$ elements in $M$ and $M^{\prime}$ strains of Drosophila melanogaster. Genet. Res. Camb. (In press). 